Check for updates

Cite this: RSC Adv., 2017, 7, 55364

Received 23rd September 2017 Accepted 26th November 2017

DOI: 10.1039/c7ra10550a

rsc.li/rsc-advances

\section{Influence of different $\beta$-nucleation agents on poly(L-lactic acid): structure, morphology, and dynamic mechanical behavior}

\author{
Lele Su, (D) a Jun Zou, ${ }^{\text {*a }}$ Shengtao Dong, (D) ${ }^{a}$ Niyuan $\mathrm{Hao}^{\mathrm{a}}$ and Haiqing $\mathrm{Xu}^{\mathrm{b}}$
}

The effects of rare earth based $\beta$-nucleating agent (WBG-II) and aryl amide derivative nucleating agent (TMB-5000) on the crystal structure, morphology, and dynamic mechanical behavior of poly(L-lactic acid) (PLLA) were systematically investigated. The presence of $\beta$-form crystal in PLLA composites has been confirmed through various techniques including wide-angle $X$-ray diffraction (WAXD), Fourier transform infrared spectroscopy (FTIR) and Raman spectroscopy. The crystallization behaviors of WBG-II and TMB-5000 nucleated PLLA were studied via WAXD and polarized optical microscope (POM) techniques. The experimental results convincingly reveal that WBG-II and TMB-5000 not only accelerate the crystallization rate, but also alter the packing structure of PLLA chains in the crystals. Furthermore, a significant difference in crystal dimensions and nucleation density was observed clearly. Moreover, the effect of different $\beta$-nucleating agents on the storage modulus $\left(E^{\prime}\right)$ and dynamic loss $(\tan \delta)$ of pure PLLA, PLLA/TMB- $5000_{0.25}$ and PLLA/WBG- $\|_{0.25}$ were investigated by dynamic mechanical analysis (DMA).

\section{Introduction}

As environmental pollution and oil crisis issues have gone from bad to worse, many research teams have dedicated considerable attention to the application of poly(lactic acid) (PLA) in the biomedical, agricultural, and general-purpose plastic fields owing to its good biocompatibility, biodegradability and processing. ${ }^{1-8}$ However, PLA based materials have their intrinsic drawbacks, such as low heat resistance temperature, slow crystallization rates, high stiffness and brittleness, which have greatly limited their further practical application on a large scale. ${ }^{9-15}$ Therefore, control over the crystallization rate and the proportion of different crystal structures in poly(L-lactic acid) (PLLA) has attracted great attention.

According to our best knowledge, the properties of a crystalline polymer are more dependent on the crystal structure and the morphology. ${ }^{16}$ It is well known to us that four different crystal structures $\left(\alpha, \alpha^{\prime}, \beta, \gamma\right)$ of PLLA have been testified, and the structure and the formation of them rest with the crystallization conditions. De Santis and Kovacs ${ }^{\mathbf{1 7}}$ first reported that the $\alpha$-form is pseudo-orthorhombic and has a $10_{3}$ helical chain conformation with crystal parameters of the unit cell dimensions of $a=1.07 \mathrm{~nm}, b=0.645 \mathrm{~nm}, c=2.78 \mathrm{~nm}$. Based on the data of WAXD and FTIR, Zhang et al. ${ }^{18}$ reported a new crystal

${ }^{a}$ School of Materials Science and Engineering, Jiangsu University of Science and Technology, Zhenjiang, 212003, P. R. China. E-mail: zj_881996@163.com; Fax: +86 511 84407381; Tel: +86 51184445783

${ }^{b}$ Jiangsu Provincial Engineering Laboratory for Advanced Materials of Salt Chemical Industry, Huaiyin Institute of Technology, Huaian, 223003, Jiangsu, P. R. China structure named the $\alpha^{\prime}$-form for PLLA crystallized under $120{ }^{\circ} \mathrm{C} .{ }^{\mathbf{1 6}}$ The chain conformation and crystal system of $\alpha^{\prime}$-form is similar to $\alpha$ structure, but it has a looser and less ordered chain packing. ${ }^{16,19,20}$ The $\beta$-form was first observed by Eling et $a .^{21}$ and researched further in numerous studies. Hoogsteen et al. ${ }^{22}$ suggested an orthorhombic unit cell for the $\beta$-form with $a=1.031 \mathrm{~nm}, b=1.821 \mathrm{~nm}, c=0.900 \mathrm{~nm}$, each arranged in a $3_{1}$ helical conformation. On the other hand, Brizzolara et $a .^{23}$ made an extensive molecular modeling and proposed an orthorhombic unit cell with two parallel chains. Subsequently, Puggiali et al. ${ }^{24}$ claimed that the $\beta$-form crystal is a frustrated structure of three $3_{1}$ helices in a trigonal unit cell with parameters of $a=b=1.052 \mathrm{~nm}, c=0.881 \mathrm{~nm}$. A more ordered crystal modification called $\gamma$ was also found by the same group. The $\gamma$ form was acquired by epitaxial crystallization of PLLA on hexamethylbenzene. ${ }^{16}$

Among these crystalline structures, the $\alpha$-form might be the most common and stable one. The particular interest in $\beta$-form arises from the fact that, the $\beta$-form has a lower melting temperature and improved mechanical properties in comparison with the $\alpha$-form. However, the $\beta$-form is thermodynamically metastable and troublesome to obtain under normal operating conditions. ${ }^{16}$ Using unique methods can obtain the $\beta$ form crystals, such as the spinning, ${ }^{25-29}$ tensile drawing, ${ }^{30,31}$ solid-state coextrusion, ${ }^{32,33}$ or adding specific nucleating agents. ${ }^{34,35}$ Eling et al. ${ }^{21}$ reported that $\beta$ crystals were produced upon tensile drawing at a high temperature to a higher draw ratio. Hoogsteen et al. ${ }^{22}$ prepared high-strength fibers which consisted of pure $\beta$-form crystals by hot drawing of solutionspun PLLA fibers. Sawai and coworkers ${ }^{32,33}$ studied the crystal 
transformation from the $\alpha$-form to the $\beta$-form during tensile drawing and solid-state extrusion, perorating that the transformation is most efficiently obtained by the orientation of PLLA at high temperatures and strain rates. Recently, Singh et $a l .{ }^{34}$ discovered the $\beta$-phase of PLLA has been established for the first time using multi-walled carbon nanotube as the template. In these techniques, the addition of $\beta$-nucleating agent is the most simple and convenient method to form the $\beta$-crystals and improve the crystallization ability of semicrystalline polymer. For example, various types of compounds have been used as $\beta$-nucleating agent for preparation of $\beta$-form isotactic polypropylene (iPP), such as organic carboxylate metal salts, ${ }^{36-38}$ the rare earth $\beta$-nucleating agents, ${ }^{39-41}$ aryl amide compounds $\mathrm{s}^{\mathbf{4 2 - 4 5}}$ and so on. Sheng et al. ${ }^{40}$ found that three types of $\beta$-crystalline morphologies are sequentially generated by adding a rare earth $\beta$-nucleating agent (WBG-II), which not only increased the overall crystallinity and the proportion of $\beta$-crystals, but also improved the toughness. Han et al. ${ }^{43}$ noted that $\beta$-form hybrid shish kebab structure was achieved in PP pipe by adding aryl amide compounds (TMB-5) as $\beta$-nucleating agent. However, little attention is paid to the $\beta$-nucleating agents to induce PLLA to form $\beta$-crystals, which is of great significance for researching the crystal structure and morphology of PLLA.

In this work, we have comparatively studied the influence of different $\beta$-nucleation agents (WBG-II and TMB-5000) on the structure, morphology, and dynamic mechanical behavior of PLLA. The incorporation of WBG-II and TMB-5000 induced the orientation of PLLA molecular chain, and then formed $\beta$-crystal, which has been revealed through wide-angle X-ray diffraction (WAXD), Fourier transform infrared spectroscopy (FTIR), and Raman spectroscopy. Moreover, the morphologies of PLLA and its composites were investigated in details with the scanning electron microscope (SEM) and polarized optical microscope (POM). At last, the relaxation behavior of PLLA and its composites through dynamic mechanical analysis (DMA) has been explored.

\section{Experimental section}

\subsection{Materials}

PLLA, Ingeo 4032D with approximately $2 \%$ D-lactide content was purchased from NatureWorks LLC, USA. Dichloromethane were procured from Sinopharm Chemical Reagent Co. Ltd. Two types of $\beta$-nucleation agents, WBG-II, and TMB-5000, were supplied by Guangdong Winner Functional Materials (China) and Hangzhou Seemore New Material Technology Co. Ltd. (China), respectively. The WBG-II has a general formula of $\mathrm{Ca}_{x} \mathrm{La}_{1-x^{-}}$ (LIG1) ${ }_{m}(\mathrm{LIG} 2)_{n}$, where $x$ and $1-x$ is the proportion of $\mathrm{Ca}^{2+}$ and $\mathrm{La}^{3+}$ ion in the complex, while LIG1 and LIG2 are respectively a dicarboxylic acid and amide-type ligand with coordination numbers of $m$ and $n$. TMB-5000 is an aryl amide derivative.

\subsection{Sample preparation}

Firstly, the PLLA were dried under vacuum at $50{ }^{\circ} \mathrm{C}$ for $24 \mathrm{~h}$. Furtherly, the mixtures ( $60 \mathrm{~g}$ ) of the PLLA and $\beta$-nucleation agents were melt-mixed for $7 \mathrm{~min}$ and then extruded by a twin-screw extruder (XRM-4000, Harbin Instrument Co. Ltd., the screw speed was $50 \mathrm{rpm}$ and the temperature of each part was 175, 185, $180{ }^{\circ} \mathrm{C}$, respectively), of which the concentration of WBG-II and TMB-5000 was adjusted to $0.25 \mathrm{wt} \%$. Henceforth, we will term the composites as PLLA/WBG-II $x$ and PLLA/TMB-5000 $x$, where $x$ represents the weight percentage of WBG-II and TMB-5000.

For the WAXD, FTIR, Raman spectroscopy, and DMA measurements, the thin-sheet samples were prepared. Firstly, the pure PLLA, PLLA/WBG- $\mathrm{II}_{0.25}$ and PLLA/TMB-5000 ${ }_{0.25}(50 \mathrm{mg})$ were hot-pressed at $200{ }^{\circ} \mathrm{C}$ to a sheet with a thickness of $200-$ $300 \mu \mathrm{m}$ on a hot plate respectively, followed by holding for $3 \mathrm{~min}$ to erase any previous thermal history. After that, the thinsheet samples were rapidly put to another hot plate, held at $120{ }^{\circ} \mathrm{C}$ for $10 \mathrm{~min}$, and finally quenched in ice ethanol.

\subsection{Testing and characterization}

2.3.1 WAXD analysis. The WAXD experiments were performed using a XRD-6000 (Shimadzu, Japan) with $\mathrm{Cu} \mathrm{K} \alpha$ radiation. The generator was operated at $36 \mathrm{kV}$ and $20 \mathrm{~mA}$. Thin polymer films were scanned at diffraction angle range from 5 to $40^{\circ}$ at a scanning rate of $2^{\circ} \mathrm{min}^{-1}$.

2.3.2 FTIR spectroscopy. The FTIR spectra were measured with a FTS 2000 (DIGILAB, America) at room temperature $\left(25^{\circ} \mathrm{C}\right)$. Optical-grade $\mathrm{KBr}$ was grounded in a mortar with a pestle, and enough solid samples were grounded with $\mathrm{KBr}$ to make $\mathrm{KBr}$ pellets. After the sample was loaded, a minimum of 32 scans was gathered for each sample at a resolution of $\pm 4 \mathrm{~cm}^{-1}$.

2.3.3 Raman spectroscopy. Raman spectra were obtained with a Invia Raman Microscope (RENISHAW, England). The $532 \mathrm{~nm}$ line of laser was used as excitation source. Scanning operations and data processing were controlled by a PC computer-controlled double monochromator. Laser power was $1.5 \mathrm{~W}$ and the integration time was $10 \mathrm{~s}$.

2.3.4 SEM observation. The scanning electron micrographs of WBG-II, TMB-5000, PLLA/WBG-II ${ }_{0.25}$ and PLLA/TMB-5000 0.25 were characterized by a JEOL field emission scanning electron microscope (model JSM-5900, Japan). PLLA/WBG-II ${ }_{0.25}$ and PLLA/TMB- $5000_{0.25}$ were the samples which were mixed in a twin-screw extruder at $180{ }^{\circ} \mathrm{C}$. All the samples were quenched with liquid nitrogen and then gold-coated before the observation.

2.3.5 POM analysis. The POM H550S (Nikon, Japan) equipped with a video camera and heat stage was used to investigate the crystalline morphology. The PLLA and its composites $(50 \mathrm{mg})$ were respectively dissolved in $10 \mathrm{~mL}$ of dichloromethane. After completely dissolution, the samples were prepared by dropping the solution on the glass slides at $50{ }^{\circ} \mathrm{C}$. Until the solvent completely evaporated, the samples were heated to $200{ }^{\circ} \mathrm{C}$ for $3 \mathrm{~min}$. Then the polarized optical micrographs of the crystals were recorded with the aid of digital camera during cooling.

2.3.6 DMA analysis. The DMA was carried out with a 242 (NETZSCH, Germany) apparatus in the tensile mode. The dynamic response was from room temperature to $140{ }^{\circ} \mathrm{C}$ at a frequency of $1 \mathrm{~Hz}$ with strain amplitude of $100 \mu \mathrm{m}$ and at a heating rate of $5 \mathrm{~K} \mathrm{~min}^{-1}$. 


\section{Results and discussion}

\subsection{Crystal structures of PLLA and its composites}

In WAXD profiles of PLLA, ${ }^{18,32,34}(010)$ at $2 \theta \approx 15^{\circ},(200) /(110)$ at $17^{\circ},(203)$ at $19^{\circ},(216)$ at $29^{\circ}$, and $(0010)$ at $31^{\circ}$ are the principal reflections of $\alpha$-form. However, the $\beta$-form crystal is a frustrated structure of three $3_{1}$ helices in a trigonal unit cell. According to the relevant papers, ${ }^{26-35}$ it appears $\beta$-peaks at $2 \theta \approx 25,26.5,27.9,29.8$ and $31^{\circ}$, of which $2 \theta \approx 29.8$ and $31^{\circ}$ corresponding to the $(330) /(003)$ and $(023)$ plane were reported relatively more. Fig. 1 represents the X-ray diffraction patterns of pure PLLA and its composites after isothermal crystallization at $120^{\circ} \mathrm{C}$ for $10 \mathrm{~min}$. It shows that four evident peaks at $2 \theta$ of approximate values $16.9,19.1,29.4,31.0^{\circ}$ are the principal reflections for $\alpha$-peaks of PLLA. The intensity of $\alpha$-peaks increases significantly with the incorporation of WBG-II and TMB-5000, indicating that the addition of $\beta$-nucleation agents improved the crystallinity of PLLA. At the same time, one can observe clearly that PLLA/WBG- $\mathrm{II}_{0.25}$ and PLLA/TMB-5000 0.25 exhibit two small reflection peaks at $2 \theta=25.1^{\circ}$ and $27.4^{\circ}$ which can be ascribed to the $\beta$-crystals. It is presumably due to that the WBG-II and TMB-5000 acted as template to induce the orientation of PLLA molecular chain and crystallized the $\beta$ form, which is further proved in our latter experiments. We also note that the peak at $2 \theta=29.4^{\circ}$ shifts to $2 \theta=29.6^{\circ}$, speculating the gradual transformation of $\alpha$-form to $\beta$-form. Hence the results reveal that the WBG-II and TMB-5000 are both effective nucleating agents, which not only can enhance the crystallization rate, but also alter the packing structure of PLLA chain in the crystals.

As far as we known, linear WAXD profiles are obtained from circular integration of intensities from 2D-WAXD. Subsequently, through deconvoluting the peaks in linear WAXD profiles, the overall crystallinity $X_{\mathrm{C}}$ was calculated by the following equation. ${ }^{46}$

$$
X_{\mathrm{C}}=\frac{\sum A_{\text {cryst }}}{\sum A_{\text {cryst }}+A_{\text {amorp }}}
$$

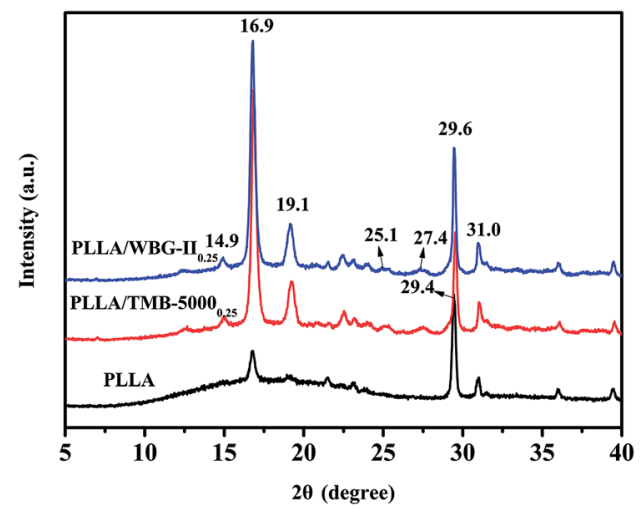

Fig. 1 Wide-angle $X$-ray diffraction (WAXD) patterns of pure PLLA, PLLA/TMB- $5000_{0.25}$, and PLLA/WBG- $-\left.1\right|_{0.25}$ after isothermally crystallized at $120{ }^{\circ} \mathrm{C}$ for $10 \mathrm{~min}$. where $A_{\text {cryst }}$ and $A_{\text {amorp }}$ are the fitted areas of crystal and amorphous peaks, respectively. The relative amount of the $\beta$ crystals $K_{\beta}$ was evaluated by the method of Turner Jones et al. ${ }^{46,47}$

$$
K_{\beta}=\frac{\sum A_{\beta}}{\sum A_{\alpha}+\sum A_{\beta}}
$$

$A_{\alpha}$ and $A_{\beta}$ are the area of $\alpha$ and $\beta$ crystal peaks, respectively. Meanwhile, the crystallinity of $\beta$-crystals $\left(X_{\beta}\right)$ can be obtained from the following equation. ${ }^{46}$

$$
X_{\beta}=K_{\beta} \times X_{\mathrm{C}}
$$

Finally, the fitted areas were obtained by Jade software. Meanwhile, the $X_{\mathrm{C}}, K_{\beta}$ and $X_{\beta}$ were calculated through above formulas, listed in Table 1 . The $X_{\mathrm{C}}$ of PLLA/WBG-II ${ }_{0.25}$ and PLLA/TMB- $5000_{0.25}$ is up to 3.9 and 3.6 times respectively, compared with that of pure PLLA. Moreover, the $K_{\beta}$ and $X_{\beta}$ values of PLLA/WBG- $\mathrm{II}_{0.25}$ are higher than that of PLLA/TMB$5000_{0.25}$. These results confirmed the fact that the incorporation of $\beta$-nucleating agent was effective to obtain the $\beta$-form crystal in PLLA matrix.

Fig. 2a manifests FTIR spectrum in the $4000-500 \mathrm{~cm}^{-1}$ region of PLLA, PLLA/TMB-5000 0.25 and PLLA/WBG- $\mathrm{II}_{0.25}$ composites at room temperature. The broad absorption peak which appear around $3504 \mathrm{~cm}^{-1}$ is assignable to $\nu(\mathrm{O}-\mathrm{H})$ vibration modes. It is well-known that hydrogen association is easy to occur in the hydroxyl, resulting in that absorption peaks shifted to lower wavenumber region and gradually widened with the increasing of the association degree. Furthermore, there are two obvious peaks appeared at about 2997 and $2946 \mathrm{~cm}^{-1}$ respectively, which are corresponding to $\nu(\mathrm{C}-\mathrm{H})$ vibration modes of methyl. Besides, the $\delta(\mathrm{C}-\mathrm{H})$ modes of methyl separately appear around 1456 and $1384 \mathrm{~cm}^{-1}$ in the spectrum. In the $\nu(\mathrm{C}=\mathrm{O})$, $\nu(\mathrm{C}-\mathrm{O})$ and $\nu(\mathrm{C}-\mathrm{C})$ regions, the PLLA and its composites exhibit sharp absorption peaks at 1760,1100 , and $1200 \mathrm{~cm}^{-1}$ respectively. Although the main characteristic absorption peaks of pure PLLA and its composites are roughly the same, there are still some differences in the spectrums, which will be discussed in details in the subsequent section.

The enlarged spectrum in the $1000-840 \mathrm{~cm}^{-1}$ region is plotted in the Fig. $2 \mathrm{~b}$. All of the PLLA and its composites present a band around $921 \mathrm{~cm}^{-1}$, which is well assigned to the coupling of $\nu(\mathrm{C}-\mathrm{C})$ and $\gamma\left(\mathrm{CH}_{3}\right)$ vibration modes and sensitive to the $10_{3}$ helix chain conformation of PLLA $\alpha$-crystals. In addition, it is interesting to find that the PLLA/TMB-5000 0.25 and PLLA/WBG$\mathrm{II}_{0.25}$ exhibit new bands at $910 \mathrm{~cm}^{-1}$ and $906 \mathrm{~cm}^{-1}$ respectively, but none of them is detected for pure PLLA. These bands are

Table 1 The $X_{C}, K_{\beta}$ and $X_{\beta}$ values of pure PLLA, PLLA/TMB-5000 0.25 and PLLA/WBG- $\|_{0.25}$

\begin{tabular}{llll}
\hline Samples & $X_{\mathrm{C}}(\%)$ & $K_{\beta}(\%)$ & $X_{\beta}(\%)$ \\
\hline PLLA & 16.25 & 0 & 0 \\
PLLA/TMB-5000 $_{0.25}$ & 59.23 & 4.81 & 2.85 \\
PLLA/WBG-II $_{0.25}$ & 64.50 & 4.95 & 3.19
\end{tabular}



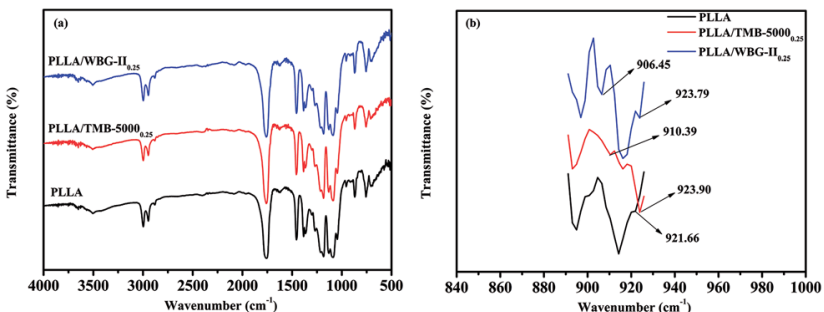

Fig. 2 (a) FTIR spectrum of pure PLLA, PLLA/TMB-5000 0.25 and PLLA/ WBG- $\|_{0.25}$ (b) the enlarged spectra in the $1000-840 \mathrm{~cm}^{-1}$.

attributed to the coupling of $\nu(\mathrm{C}-\mathrm{C})$ and $\gamma\left(\mathrm{CH}_{3}\right)$ vibration modes of $\beta$ crystals $\left(3_{1}\right.$ helix), ${ }^{18}$ which suggested that the $\beta$-form had been established by using WBG-II and TMB-5000 as template. Compared with that of TMB-5000, the WBG-II performed a better nucleation effect.

The Raman curves of pure PLLA, PLLA/TMB-5000 0.25 and PLLA/WBG-II ${ }_{0.25}$ composites are displayed in Fig. 3a. According to literature, ${ }^{48}$ the $3004,2950,2884$, and $2741 \mathrm{~cm}^{-1}$ peaks were observed in PLLA and its composites could be assigned to $\nu(\mathrm{C}-$ $\mathrm{H})$ vibration modes of methyl. The $\delta(\mathrm{C}-\mathrm{H})$ vibration modes of methyl appear at 1457, 1388, and $1299 \mathrm{~cm}^{-1}$. The peaks appeared at about 1773 and $1519 \mathrm{~cm}^{-1}$ are corresponding to $\nu(\mathrm{C}=\mathrm{O})$ vibration modes. The $\nu(\mathrm{O}-\mathrm{C}-\mathrm{O})$ modes are observed at 1127 and $1042 \mathrm{~cm}^{-1}$. Furthermore, the Raman line assigned to $\nu(\mathrm{C}-\mathrm{C})$ vibration modes are observed at 1183, 1094, 740, $709 \mathrm{~cm}^{-1}$ in Raman spectrum, respectively.

In addition, the enlarged spectrum in $965-835 \mathrm{~cm}^{-1}$ region is presented in Fig. $3 \mathrm{~b}$. The most intensive Raman characteristic peaks are located at $c a .873 \mathrm{~cm}^{-1}$ in the Raman spectrum, which could be assigned to $\nu(\mathrm{C}-\mathrm{COO})$ mode. Moreover, the 921 and $907 \mathrm{~cm}^{-1}$ doublet could be seen in the Raman spectrum of PLLA/TMB-5000 0.25 and PLLA/WBG- $\mathrm{II}_{0.25}$ composites. The former band reflects to the $10_{3}$ helix, whereas the latter one reflects to the $3_{1}$ helix. They are assigned to the coupling of the $\nu(\mathrm{C}-\mathrm{C})$ and $\gamma\left(\mathrm{CH}_{3}\right)$ vibration modes. It is simple to distinguish $10_{3}$ ( $\alpha$ crystals) and $3_{1}$ ( $\beta$ crystals) helical conformations of PLLA in Raman spectrum, which seems more sensitive to molecular segment arrangement. Meanwhile, compared with PLLA/TMB$5000_{0.25}$, PLLA/WBG-II ${ }_{0.25}$ composite has higher strength of $\beta$-phase peak, which indicates that WBG-II has better nucleation effect, and induces PLLA to form higher content $\beta$-form crystal. These results are in accordance with those of WAXD and FTIR discussed before.
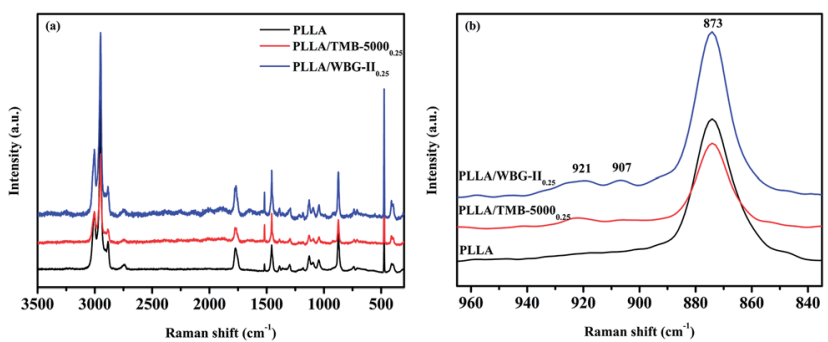

Fig. 3 (a) Raman spectrum of pure PLLA, PLLA/TMB-5000 0.25 and PLLA/WBG- $\|_{0.25}$, (b) the enlarged spectra in the $965-835 \mathrm{~cm}^{-1}$.

\subsection{Morphologies of PLLA and its composites}

The scanning electron micrographs of WBG-II, TMB-5000, PLLA/WBG-II ${ }_{0.25}$ and PLLA/TMB-5000 0.25 are showed in Fig. 4. It shows that particles of WBG-II adopt an irregular block-like crystal morphology whose single crystal diameter is about tens of nanometers in Fig. 4a. TMB-5000 is a kind of strip-like crystal whose single crystal diameter is relatively larger than WBG-II, as shown in Fig. 4b. In addition, the morphologies of PLLA/WBG-II ${ }_{0.25}$ and PLLA/TMB-5000 $0_{0.25}$ show the dispersion states of WBG-II and TMB-5000 in the PLLA matrix in Fig. 4c and $d$ respectively. It is clearly to see that a large number of tiny monocrystals of WBG-II are widely dispersed in PLLA matrix while relatively few strip-like crystals of TMB-5000 are dispersed in PLLA matrix, indicating that WBG-II disperses in the PLLA matrix more intensively than TMB-5000.

Generally, the nucleation rate and growth rate of crystals both have effects on the crystallization of polymers. Therefore, the crystalline morphologies of pure PLLA, PLLA/TMB-5000 0.25 and PLLA/WBG-II $\mathrm{I}_{0.25}$ composites have been investigated in details by POM. The samples were prepared by melting on a hot plate, and rapidly cooled to $120{ }^{\circ} \mathrm{C}$, then maintained for different time.

As showed in Fig. 5a and b, the crystallization rate is slow and the spherulites size is relatively large in pure PLLA, which is due to that the formation of nuclei is difficult and spherulite growth is mainly a homogeneous nucleation. In Fig. $5 \mathrm{c}$ and e, it is a little dark in the visual field which crystallized at $120^{\circ} \mathrm{C}$ for $1 \mathrm{~min}$, and considerable small crystals could be identified, then it becomes lighter in Fig. 5d and f which crystallized for $3 \mathrm{~min}$. These results indicate that the crystallization rate becomes faster, and the crystals become much smaller in $\beta$-nucleated PLLA, which is attributed to the fact that a large amount of nuclei produced after adding the nucleating agent in heterogeneous nucleation. In comparison with that of TMB-5000, the WBG-II acted as a more effective nucleating agent to initiate nucleation and increase the nucleation density for PLLA crystallization. The main reason may be that the size of WBG-II is

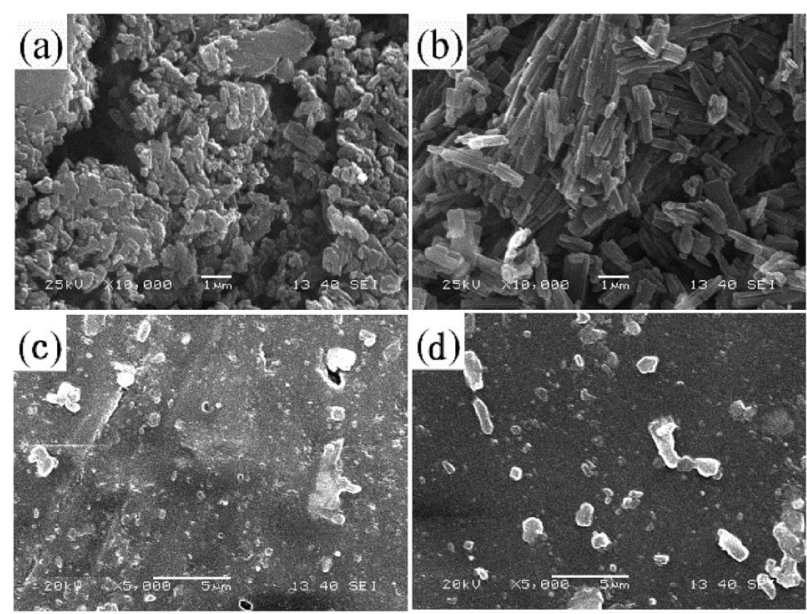

Fig. 4 Scanning electron micrographs of (a) WBG-II, (b) TMB-5000, (c) PLLA/WBG- $\mid \|_{0.25}$, (d) PLLA/TMB-5000 0.25 . 


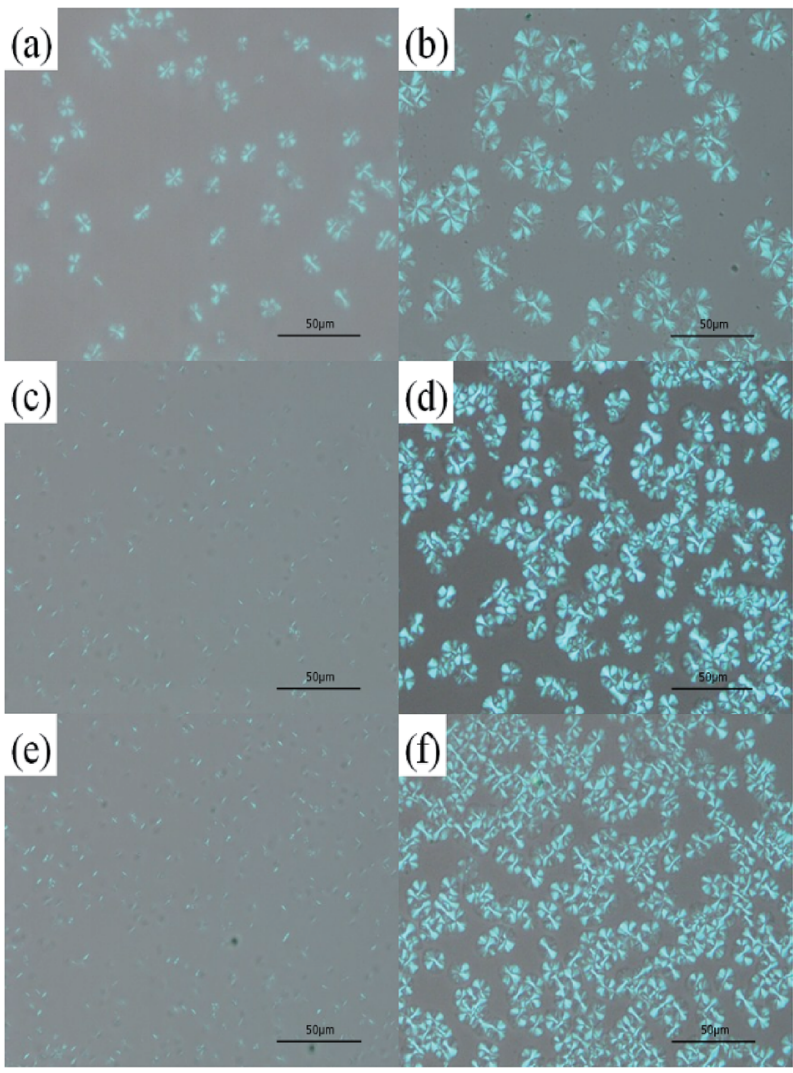

Fig. 5 Polarized optical micrographs of PLLA and its composites at $120^{\circ} \mathrm{C}$ for different time. (a) PLLA for $2 \mathrm{~min}$, (b) PLLA for $5 \mathrm{~min}$, (c) PLLA/ TMB- $5000_{0.25}$ for $1 \mathrm{~min}$, (d) PLLA/TMB-5000 0.25 for 3 min, (e) PLLA/ WBG- $\mid I_{0.25}$ for $1 \mathrm{~min}$, (f) PLLA/WBG- $\|_{0.25}$ for $3 \mathrm{~min}$.

relatively small, so it disperses in the PLLA matrix more intensively, which have been showed in Fig. $4 \mathrm{c}$ and d, and finally favors the formation of high proportion of crystals. In addition, the crystalline morphologies of pure PLLA are obviously different from the samples containing WBG-II and TMB-5000. Distinctly, the spherulites of PLLA are typical birefringence, while the agglomerates of PLLA/TMB-5000 0.25 and PLLA/WBG$\mathrm{II}_{0.25}$ composites appear bundle-like structure, which have been reported by Sheng's group..$^{40}$ Sheng et al. found that the bundlelike crystals emerged which is one of the types of $\beta$-crystalline morphologies when the content of WBG in iPP increased to $0.25 \mathrm{wt} \%$ and $0.5 \mathrm{wt} \%$. In this way, the special morphology may be the formation of $\beta$-crystals, which will be testified later.

Fig. 6 shows the crystalline morphologies at $130{ }^{\circ} \mathrm{C}$ and $140^{\circ} \mathrm{C}$ for the PLLA and its composites after saturation of crystal formation. The crystal dimension of the PLLA and its composites considerably increases with the increase of $T_{\mathrm{c}}$. Moreover, the size of the crystal decreases with the incorporation of WBG-II and TMB-5000, which is in good consistance with the previous paragraph. This again illustrates that the crystallization rate of PLLA/TMB-5000 0.25 and PLLA/WBG-II ${ }_{0.25}$ composites is faster than that of pure PLLA at the same $T_{\mathrm{c}}$. Additionally, it is worthwhile mentioning that the bundle-like structure with higher birefringent forms on the surface of $\beta$-nucleated PLLA crystals is shown clearly in the Fig. $6 \mathrm{~d}$ and $\mathrm{f}$. This phenomenon

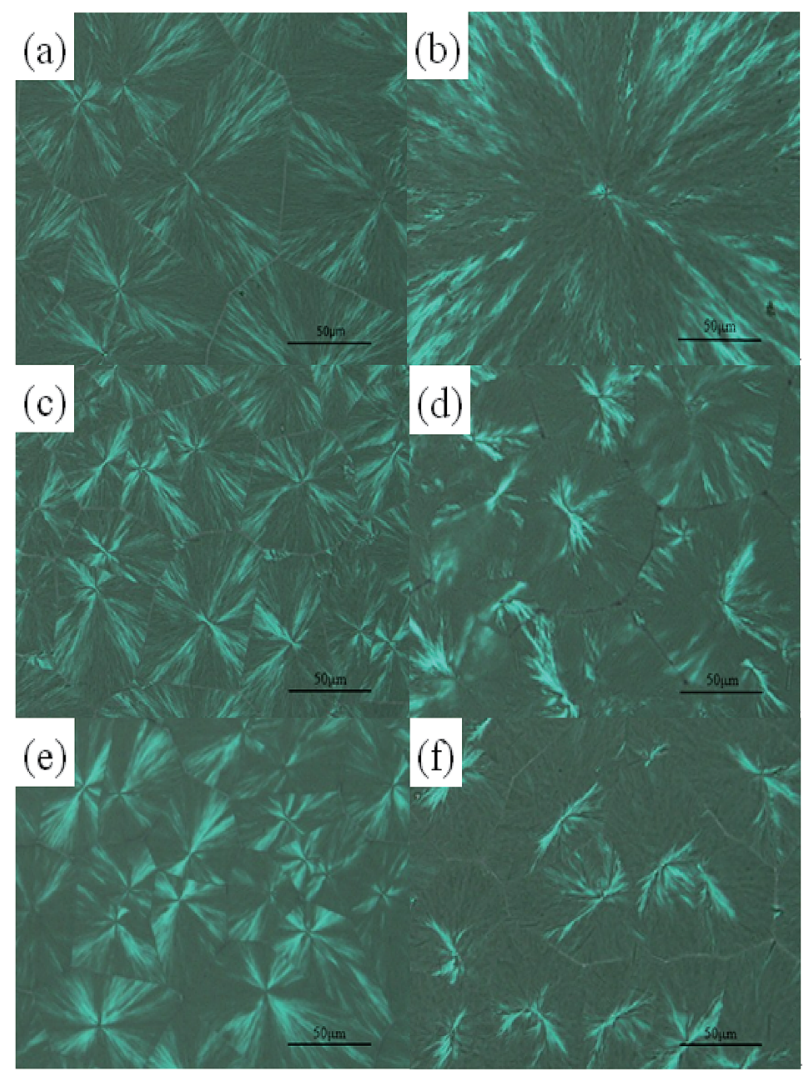

Fig. 6 Polarized optical micrographs of PLLA and its composites crystallized at different temperature. (a) PLLA, (c) PLLA/TMB-5000 0.25 , (e) PLLA/WBG- $\|_{0.25}$ isothermally crystallized at $130{ }^{\circ} \mathrm{C}$; (b) PLLA, (d) PLLA/TMB-5000 0.25 , (f) PLLA/WBG- $\|_{0.25}$ isothermally crystallized at $140{ }^{\circ} \mathrm{C}$.

can be attributed to the solubility of WBG-II and TMB-5000 in PLLA at melt temperature, and the self-organization and recrystallization of molten WBG-II and TMB-5000 from PLLA matrix. Therefore, it can be inferred the coexistence of two different crystalline forms, including $\alpha$-form and $\beta$-form, which is in agreement with the results of WAXD, FTIR and Raman spectroscopy.

\subsection{Dynamic mechanical behavior of PLLA and its composites}

Fig. 7 demonstrates the storage modulus $\left(E^{\prime}\right)$ and dynamic loss $(\tan \delta$ ) curves as a function of temperature for pure PLLA, PLLA/ TMB-5000 0.25 and PLLA/WBG-II ${ }_{0.25}$ composites. The pure PLLA has higher modulus than both of PLLA/WBG- $\mathrm{II}_{0.25}$ and PLLA/ TMB- $5000_{0.25}$ composites when the temperature is less than $60{ }^{\circ} \mathrm{C}$, indicating that the $\beta$-nucleation agents have decreased the storage modulus of PLLA matrix. On the one hand, the decrease of crystal dimension of PLLA composites that has been showed in polarized optical micrographs reduced the rigidity of the material. On the other hand, it may be the existence of $\beta$-crystal in the PLLA/WBG- $\mathrm{II}_{0.25}$ and PLLA/TMB-5000 0.25 composites. Then, the $E^{\prime}$ value of pure PLLA and its composites dropped abruptly in the range of $50-70{ }^{\circ} \mathrm{C}$. The pure PLLA and 

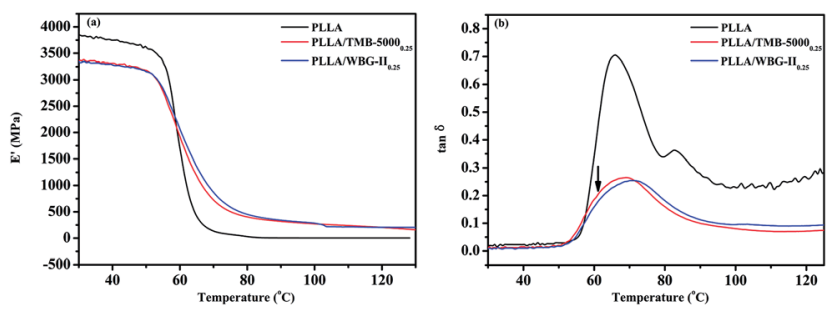

Fig. 7 Dynamic mechanical responses of pure PLLA, PLLA/TMB$5000_{0.25}$ and PLLA/WBG- $\|_{0.25}$ (a) storage modulus $\left(E^{\prime}\right)$, (b) dynamic loss $(\tan \delta$ ) curves as a function of temperature in tensile mode.

its composites become soft when the temperature is above their glass-transition temperatures, while PLLA/TMB-5000 0.25 and PLLA/WBG-II ${ }_{0.25}$ composites show a greater storage modulus as compared with pure PLLA due to the higher crystallinity.

From the figure with dynamic loss curves in Fig. 7b, it is of great obvious that the $T_{\mathrm{g}}$ peak of PLLA is sharp and high, suggesting that the segment relaxation is quite difficult. In contrary, the $T_{\mathrm{g}}$ peak of PLLA/TMB-5000 0.25 and PLLA/WBG$\mathrm{II}_{0.25}$ composites is comparatively broad and low, which can be explained by the fact that the crystallinity of PLLA/TMB- $5000_{0.25}$ and PLLA/WBG-II ${ }_{0.25}$ composites was greatly improved and the packing of helices was more ordered, leading to the decrease of friction loss. However, the $T_{\mathrm{g}}$ value corresponding to the composites increases slightly. The $T_{\mathrm{g}}$ value of pure PLLA is $66.0^{\circ} \mathrm{C}$, whereas the $T_{\mathrm{g}}$ value for PLLA/TMB-5000 0.25 is $68.9^{\circ} \mathrm{C}$, and that for PLLA/WBG-II ${ }_{0.25}$ is $71.3{ }^{\circ} \mathrm{C}$. The closer packing of helices for PLLA/WBG-II $\mathrm{I}_{0.25}$ impeded the movement of chain segments below the glass-transition temperature, so a higher $T_{\mathrm{g}}$ value was observed for PLLA/WBG-II ${ }_{0.25}$ as compared with that of PLLA/TMB- $5000_{0.25}$. It is interesting to find that the composites show a small hump at $65.0{ }^{\circ} \mathrm{C}$ which is absent in pure PLLA. It is probably due to the relaxation behavior of $\beta$-form crystals, as the arrow indicated. In fact, $\beta$-form crystal structure has a lower thermal stability than $\alpha$-form crystal structure corresponding to a certain degree of disorder in the crystals. Therefore, the above results of DMA also reveal that the incorporation of $\beta$-nucleating agent is effective to obtain the $\beta$-form crystal in PLLA matrix and WBG-II performed a better nucleation effect than TMB-5000.

\section{Conclusions}

The effects of WBG-II and TMB-5000 on the $\beta$-form crystal structure, crystallization behavior, and dynamic mechanical responses of the PLLA were investigated in details. WBG-II and TMB-5000 are both effective nucleating agents, which not only can accelerate the crystallization rate, but also alter the packing structure of PLLA chain in the crystals. In comparison with that of TMB-5000, WBG-II acted as a more effective nucleating agent to initiate nucleation and increase the nucleation density for PLLA crystallization. The crystal structures of PLLA and its composites studied by WAXD, FTIR and Raman spectroscopy show that WBG-II and TMB-5000 can act as template to induce the orientation of PLLA molecular chain and crystallize the $\beta$-form crystal in PLLA matrix. Moreover, the $K_{\beta}$ and $X_{\beta}$ values of PLLA/WBG-II ${ }_{0.25}$ are higher than that of PLLA/TMB-5000 0.25 . In addition, the dynamic mechanical responses of pure PLLA, PLLA/TMB-5000 0.25 and PLLA/WBG- $\mathrm{II}_{0.25}$ indicate that the change of mechanical and thermal properties is related to the relaxation behavior of $\beta$-form and crystallinity of PLLA. Thus, the discovery of WBG-II and TMB-5000 as $\beta$-nucleating agent for PLLA might broaden its real application in the traditional fields.

\section{Conflicts of interest}

There are no conflicts to declare.

\section{Acknowledgements}

This work was financially supported by the Opening Project of Key Laboratory for Palygorskite Science and Applied Technology of Jiangsu Province (HPK201605), Huaian Science and Technology project (HAS2015002), the Open Project Fund for Jiangsu Provincial Engineering Laboratory for Advanced Materials of Salt Chemical Industry (No. 2065031701) and A Project Funded by the Priority Academic Program Development of Jiangsu Higher Education Institutions (PAPD).

\section{Notes and references}

1 D. Garlotta, J. Polym. Environ., 2001, 9, 63-84.

2 R. Auras, B. Harte and S. Selke, Macromol. Biosci., 2004, 4, 835-864.

3 R. Bhardwaj and A. K. Mohanty, J. Biobased Mater. Bioenergy, 2007, 1, 191-209.

4 C. K. Williams and M. A. Hillmyer, Polym. Rev., 2008, 48, 110.

5 P. Ma, T. Shen, P. Xu, W. Dong, P. J. Lemstra and M. Chen, ACS Sustainable Chem. Eng., 2015, 3, 1470-1478.

6 K. Zhang, J.-K. Peng, Y.-D. Shi, Y.-F. Chen, J.-B. Zeng and M. Wang, J. Phys. Chem. B, 2016, 120, 7423-7437.

7 L. Genovese, M. Soccio, N. Lotti, M. Gazzano, V. Siracusa, E. Salatelli, F. Balestra and A. Munari, Eur. Polym. J., 2017, 95, 289-303.

8 Y. Liu, S. Wang and R. Zhang, Int. J. Biol. Macromol., 2017, 103, 1130-1137.

9 M. Yasuniwa, S. Tsubakihara, K. Iura, Y. Ono, Y. Dan and K. Takahashi, Polymer, 2006, 47, 7554-7563.

10 Y. Song, K. Tashiro, D. Xu, J. Liu and Y. Bin, Polymer, 2013, 54, 3417-3425.

11 L. Lim, R. Auras and M. Rubino, Prog. Polym. Sci., 2008, 33, 820-852.

12 A. P. Johari, S. K. Kurmvanshi, S. Mohanty and S. K. Nayak, Int. J. Biol. Macromol., 2016, 84, 329-339.

13 P. Xu, P. Ma, M. Hoch, E. Arnoldi, X. Cai, W. Dong and M. Chen, Polym. Degrad. Stab., 2016, 129, 328-337.

$14 \mathrm{~J}$. Zeng, K. Li and A. Du, RSC Adv., 2015, 5, 32546-32565.

15 M. Wang, Y. Wu, Y.-D. Li and J.-B. Zeng, Polym. Rev., 2017, 57, 557-593.

16 S. Saeidlou, M. A. Huneault, H. Li and C. B. Park, Prog. Polym. Sci., 2012, 37, 1657-1677. 
17 P. De Santis and A. J. Kovacs, Biopolymers, 1968, 6, 299-306. 18 J. Zhang, Y. Duan, H. Sato, H. Tsuji, I. Noda, S. Yan and Y. Ozaki, Macromolecules, 2005, 38, 8012-8021.

19 M. Cocca, M. L. Di Lorenzo, M. Malinconico and V. Frezza, Eur. Polym. J., 2011, 47, 1073-1080.

20 J. P. Kalish, K. Aou, X. Yang and S. L. Hsu, Polymer, 2011, 52, 814-821.

21 B. Eling, S. Gogolewski and A. J. Pennings, Polymer, 1982, 23, 1587-1593.

22 W. Hoogsteen, A. R. Postema, A. J. Pennings, G. ten Brinke and P. Zugenmaier, Macromolecules, 1990, 23, 634-642.

23 D. Brizzolara, H.-J. Cantow, K. Diederichs, E. Keller and A. J. Domb, Macromolecules, 1996, 29, 191-197.

24 J. Puiggali, Y. Ikada, H. Tsuji, L. Cartier, T. Okihara and B. Lotz, Polymer, 2000, 41, 8921-8930.

25 J. W. Leenslag and A. J. Pennings, Polymer, 1987, 28, 16951702.

26 H. J. Zhou, K. W. Kim, E. Giannelis and Y. Joo, Polymer, 2006, 918, 217-230.

27 H. Zhou, T. B. Green and Y. L. Joo, Polymer, 2006, 47, 74977505.

28 P. H. S. Picciani, E. S. Medeiros, Z. Pan, W. J. Orts, L. H. C. Mattoso and B. G. Soares, J. Appl. Polym. Sci., 2009, 112, 744-753.

29 A. R. Cho, D. M. Shin, H. W. Jung, J. C. Hyun, J. S. Lee, D. Cho and Y. L. Joo, J. Appl. Polym. Sci., 2010, 120, 752-758.

30 K. Takahashi, D. Sawai, T. Yokoyama, T. Kanamoto and S.-H. Hyon, Polymer, 2004, 45, 4969-4976.

31 H. M. De Oca and I. M. Ward, J. Polym. Sci., Part B: Polym. Phys., 2007, 45, 892-902.

32 D. Sawai, K. Takahashi, A. Sasashige, T. Kanamoto and S.-H. Hyon, Macromolecules, 2003, 36, 3601-3605.
33 D. Sawai, K. Takahashi, T. Imamura, K. Nakamura, T. Kanamoto and S. H. Hyon, J. Polym. Sci., Part B: Polym. Phys., 2003, 40, 95-104.

34 N. Singh, S. Singh, D. Dash, A. Mohanty, M. Misra and P. Maiti, J. Phys. Chem. C, 2013, 117, 10163-10174.

35 W. Wu, X. Cao, Y. Zhang and G. He, J. Appl. Polym. Sci., 2013, 130, 443-452.

36 Z. Zhang, C. Chen, C. Wang, Z. Junping and K. Mai, Polym. Int., 2010, 59, 1199-1204.

37 Z. Zhang, Y. Tao, Z. Yang and K. Mai, Eur. Polym. J., 2008, 44, 1955-1961.

38 S. Zhao, Z. Cai and Z. Xin, Polymer, 2008, 49, 2745-2754.

39 F. Luo, C. Geng, K. Wang, H. Deng, F. Chen, Q. Fu and B. Na, Macromolecules, 2009, 42, 9325-9331.

40 Q. Sheng, y. Zhang, C. Xia, D. Mi, X. Xu, T. Wang and J. Zhang, Mater. Des., 2016, 95, 247-255.

41 X. Xu, X.-P. Li, B.-Q. Jin, Q. Sheng, T. Wang and J. Zhang, Polym. Test., 2016, 51, 13-19.

42 Y.-H. Chen, Z.-Y. Huang, Z.-M. Li, J.-H. Tang and B. Hsiao, RSC Adv., 2014, 4, 14766-14776.

43 R. Han, M. Nie and Q. Wang, J. Taiwan Inst. Chem. Eng., 2015, 52, 158-164.

44 M. Li, G. Li, Z. Zhang, X. Dai and K. Mai, Thermochim. Acta, 2014, 598, 36-44.

45 S. Shi, X. Zhang, Y. Liu, M. Nie and Q. Wang, Compos. Sci. Technol., 2016, 135, 76-82.

46 Y. Chen, Y. Mao, Z. Li and B. S. Hsiao, Macromolecules, 2010, 43, 6760-6771.

47 A. Turner-Jones and A. J. M. Cobbold, J. Polym. Sci., Part B: Polym. Lett., 1968, 6, 539-546.

48 G. Kister, G. Cassanas and M. Vert, Polymer, 1998, 39, 267273. 